\title{
QUALITY CHANGES IN SPERMATOZOA OF EXOTIC MUZAFFARNAGARI CROSS-BREED RAM SEMEN DURING THE STAGES OF FROZEN PRODUCTION
}

\author{
Mohammad ASADUZZAMAN1, Amit SAHA², Suravi AKTER², Shankar BISWAS², Md. Golam Shahi ALAM² and \\ Farida Yeasmin BARI2
}

1 Upazilla Livestock Officer, Department of Livestock Services, Farmgate, Dhaka-1215, Bangladesh

${ }^{2}$ Department of Surgery and Obstetrics, Bangladesh Agricultural University, Mymensingh-2202, Bangladesh

Email: faridabari06@gmail.com; (D) ORCiD: 0000-0002-1574-9263

\begin{abstract}
Good quality frozen semen is a prerequisite for successful artificial insemination. Changes in the quality of sperm structure incur during semen processing of cryo-production. The current study, is, therefore, designed to evaluate the Muzaffarnagari cross-breed ram sperm at the fresh diluted stage, pre-freeze, and after freezing stages of frozen production. The semen collected was enlarged to include the A-part of $37^{\circ} \mathrm{C}$ egg yolk media. After cooling to $5^{\circ} \mathrm{C}$ for $2 \mathrm{~h}$, B-part of tris-citric acid egg yolk glycerol media added with Apart and equilibrated at $5^{\circ} \mathrm{C}$ for further $2 \mathrm{~h}$, transferred to $0.25 \mathrm{~mL}$ straws, placed in nitrogen vapor, frozen and thawed and then analyzed. Sperm samples were assessed in fresh, pre-freezing, and post Thawing phases for sperm motility, live sperm, ordinary sperm morphology, and intact sperm membrane. The mean percentage of sperm motility at fresh diluted stage $(81.67 \pm 0.93 \%)$ was decreased significantly $(p<0.05)$ pre-freezing stage $(77.33 \pm 0.83 \%)$ because of refreshment and balance, and after freezing and thawing $(44 \pm 2.45$ percent) decreased further $(p<0.05)$. The Mean percentage of live sperm was higher $(p<0.05)$ at fresh diluted stage $(91.27 \pm 0.57 \%)$ compared to pre-freeze $(73.67 \pm 0.86 \%)$ and freezing stage $(48.1 \pm 0.76 \%)$. The morphology normal sperm reduced significantly $(p<0.05)$ from fresh diluted stage $(85.27 \pm 0.64 \%)$ to pre-freezing stage $(83.13 \pm 0.74)$. Their difference between the pre-freezing and the freezing stage is not significant $(p>0.05)$ $(80.2 \pm 1.28$ percent). The mean intact sperm membrane percentage decreased significantly $(p<0.05)$ from freshly diluted $(82.4 \pm 0.77 \%)$ to pre-freezing $(69.73 \pm 92 \%)$ and post-freezing $(56.47 \pm 1.15 \%)$, respectively. The percentage of intact acrosomes of spermatozoa also significantly $(p<0.05)$ decreased from fresh stage $(95.8 \pm 0.39 \%)$ to pre-freeze $(91.27 \pm 0.37 \%)$ and freezing stage $(77.4 \pm 0.81 \%)$. In conclusion, during cryofreezing periods the sperm showed the highest motility, live and membrane damage.
\end{abstract}

Keywords: Frozen production, Muzaffarnagari cross-breed ram, Quality changes.

\section{INTRODUCTION}

The exploitation of the male line using fresh and frozen semen through artificial insemination is important reproductive biotechnology in selective breeding. The quality of fresh semen starts to decline while the sperm come outside the body. Ejaculate sperm survival is restricted to just a few hours in seminal plasma alone. Dilution is necessary for the long protection of sperm and survivability (Ax et al., 2000). When diluted semen cools, the metabolic rate of sperm deprives and therefore prolongs the survival of sperm (Curry, 2000; Colenbrander et al., 2003; Cremades et al., 2005). The distance of semen collection and insemination sites, diseases transmission, the possibility of covering a large number of females in a short period, the cryo-preservation is a subject of permanent interest for extensive use of artificial insemination.

Cryopreservation (Purdy, 2006) is a complex process involving several related factors such as freezing, dilution, cooling rates, and tanning techniques (Aboagla and Terada, 2004). According to the report of Watson (2000), Significant damage to sperm occurs during cryopreservation. Dramatic changes to the temperature, osmotic and toxic stress causing ultrastructural, biological, and functional damage to the sperm caused by ice formation and dissolution in intracellular and extracellular environments (Leboeuf et al., 2000, Medeiros et al., 2002). As a consequence, sperm, cell cytoplasm fractures, even cytoskeletal or genome structures, are damaged (Isachenko et al., 2003). These effects would ultimately reduce motility, viability, transport impairment, and fertility (Leboeuf et al., 2000). Semen evaluation aims mainly to predict its fertilization ability (Britto et al., 2003).

Many recent studies show that the potential of sperm fertilization depends on the integrity and functioning of cells. To be able to permeate the sperm into a pellucid zone and fuse the oocytes (Oura and Toshimori, 1990; Flesch and Gadella 2000), it is essential to achieve acrosomal integrity for fertilization of oocytes. Integrity is critical for oocytes. The plasma membrane preserves cellular homeostasis and therefore plays an essential role in the survival and maintenance of the female reproductive tract's sperm membrane fertility (Oura and Toshimori, 1990). For sperm fertilization, a functional membrane is required because it plays a major role in sperm capacity, acrosome reactions, and egg surface binding (Ramu et al., 2013). The evaluation can provide a useful sperm fertility indicator (Agarwal et al., 2016).

Methods of cryo-preservation of indigenous ram semen already optimized in the reproduction laboratory of the Department of Surgery and Obstetrics, Bangladesh Agricultural University, Mymensingh. However, to our knowledge, there 
is no information on cryopreservation of exotic Muzaffarnagari cross breed ram semen in Bangladesh. Therefore, the present research work was designed to know the quality changes in sperm motility, live, normal morphology, intact membrane, and intact acrosome of exotic Muzaffarnagari cross breed ram semen during stages of cryo-production.

\section{MATERIALS AND METHODS}

\section{Study location}

The study was conducted at the Department of Surgery and Obstetrics, Bangladesh Agricultural University (BAU), Bangladesh from September to December 2018. The university is located at N 24.73 latitude and E 90.44 longitude, and $9 \mathrm{~m}$ above sea level. The area receives on average $174 \mathrm{~mm}$ of rainfall with the mean annual minimum and maximum temperatures range from 16.46 to $29.13^{\circ} \mathrm{C}$, respectively.

\section{Ethical regulation}

Animal Experimental Ethics Committee (AEEC) of BAU, Mymensingh, Bangladesh (Ref. no. AEEC/ DSO-BAU/04/ 2019) approved the study protocols.

\section{Animal and management}

For this study, three cross-breed Muzaffarnagari rams of 1.5-4 years were selected and maintained in Sheep Research Farm, Bangladesh University, Mymensingh. The rams were given a supplement of about 300 gm containing maize grains, wheat bran with di-calcium phosphate, and salt was grazed daily for 6 to 7 hours grazing. They have been routinely given safe drinking water three times a day.

\section{Reagents and extender preparation}

Eosin and nigrosin stain was prepared following the procedure of Evan and Salmons (1987). The hypo-osmotic solution was prepared using the protocol used by Jeyendran et al (1992). Formal citrate solution was prepared according to the formula used by Cabrera et al. (2005). Giemsa stain was made ready as per protocol used in VGO 511 (2012). TCEYG (Tris Citrate Egg Yolk Glycerol) extender was prepared on the day of semen collection following the formula and procedure used by Zohara et al. (2014) and Archarya, (2017). Sigma-Aldrich ${ }^{\circledR}$ (Chemie Steinheim ${ }^{\circ}$, Germany), Merck, Research -lab Fine Chemicals Industries (Mumbai, India), ACME Laboratories Ltd. were the chemical sources used for reagents and extenders (Dhaka, Bangladesh).

\section{Semen collection}

Under sterile and dry conditions, all equipment used for the collection of semen was maintained until use. The artificial vagina (AV) was produced by assembling a stern, smooth, latex cone (12"), a gradient collection tube (6"). The artificial vagina was inserted into a sterile soft rubber external cylinder (20 cm long and $5 \mathrm{~cm}$ broad in diameter or 8 ") [ (Vishal, 2014). A known helping man in a welcoming environment collected semen (replicates $=5$ ) with a $52^{\circ} \mathrm{C}$ artificial vagina twice a week. Each ejaculate was transferred immediately after collection for microscopic evaluation and subsequent treatment in a water bath at $37^{\circ} \mathrm{C}$.

\section{Semen processing and quality assay}

Each semen sample ( 3 rams $x 5$ replicates $=15$ samples) was evaluated for sperm motility, live sperm, normal sperm morphology, plasma membrane integrity, and acrosome integrity changes during at fresh stage, before freezing, and after thawing. Semen samples were diluted with TCEYG extenders and freeze using the protocol of Jha et al. (2019) with a sperm concentration of 200 million sperm $/ \mathbf{m L}$. The freeze semen straws were analyzed after thawing at 37 ${ }^{\circ} \mathrm{C}$ for $30 \mathrm{~s}$.

\section{Sperm motility}

A small drop $(5 \mu \mathrm{l})$ of diluted semen sample (dilution 1: 10 in pre-warmed tris-citrate solution) was placed on warm glass slides $\left(37^{\circ} \mathrm{C}\right)$ with a clean, dried pre-warmed cover slide $(18 \times 18 \mathrm{~mm})$ and examined under the light microscope (X40). The percentage of motile sperm was assessed subjectively by viewing 3-5 fields per slide. The motile sperm percentage was estimated to be the next $5 \%$ and $0-100 \%$ (Moghaddam et al., 2012).

\section{Live-dead percentage}

Live-dead Sperm were assayed by Eosin-nigrosin staining as of Soltanpour and Moghaddam (2013) with some modification. A small drop $(5 \mu \mathrm{l})$ of semen sample was mixed with a large drop $(20 \mu \mathrm{l})$ of pre-warmed $\left(37^{\circ} \mathrm{C}\right)$ eosinnigrosin stain in the Eppendorf tube. With a small drop of mixed semen, a smooth, greaseless, homogenous, thin smear was prepared using another slid glass slide. The smear was observed at $40 \mathrm{X}$ and microphotographs were taken at optical zoom magnification. An 8-10 focuses were saved to count 200 spermatozoa. Unstained spermatozoa are considered to live and spermatozoa stained pink against a brownish-purple background are considered dead.

\section{Normal sperm morphology percentage}

Sperm morphology was evaluated using the same eosin-nigrosine stained slide to screen morphological abnormalities (Vishal, 2014, Sitali et al., 2017, Rai et al., 2020). The captured microphotographs were used for studying the abnormalities.

\section{Intact membrane percentage}

A semen sample and HOS solution $(190 \mu \mathrm{L}$ 0smol/ $\mathrm{kg}$ ) were mixed as $50 \mu \mathrm{L}$ : $500 \mu \mathrm{L}$. A $5 \mu \mathrm{L}$ semen drop following incubation was smeared and investigated in a light microscope (X40). The sperm micro-photograph with optical zoom magnification has been studied for coiling or swelling of the tail of different degrees as intact acrosome. The total intactness of the plasma membranes was the count for 100 sperms (Jeyendran et al., 1984; Ahmad et al., 2014). 


\section{Intact acrosome percentage}

The sperm acrosomal damage was studied in Giemsa stained smears in step with the tactic represented by VGO 511 (2012) and Barth and Oko (1989). In brief, the semen sample was diluted (1:10) with freshly prepared $2.9 \%$ sodium citrate buffer in a $1.5 \mathrm{ml}$ Eppendorf tube. A smear was prepared with a drop of diluted semen on a clean, grease-free, prewarmed glass slide and air-dried. The smear slide was immersed into a $5 \%$ formaldehyde solution for fixing at $37^{\circ} \mathrm{C}$ for $30 \mathrm{~min}$. After removal from the solution, the slide was washed in running tap water and air-dried. The smear slide was immersed in the working Giemsa solution overnight (Mir et al., 2012). The slides were removed from the stain and washed in running tap water, and then air-dried. Then the sperm were observed at 40X and microphotographs were taken at optical zoom magnification. At least 200 sperms were counted consist of normal, partially lost, complete lost, ruffled or wrinkled, knobbed, detached galeacapitis, apical notch acrosome from the different focus of a slide.

\section{Statistical analysis}

Data were first tabulated and grouped on the Microsoft Excel worksheet. Descriptive statistics were then used to establish mean $( \pm$ SEM) values for studied parameters. ANOVA: Single Factor was used to analyze their differences between cryopreservation stages using the Excel analysis tools pack. The alpha level, $p<0.05$ was considered significant.

\section{RESULTS}

The changes in sperm motility, live sperm, normal sperm morphology, plasma membrane integrity, and acrosome integrity at the subsequent stages of cryo-preservation of Muzaffarnagari cross-breed ram semen are presented in Figure $1,2,3,4$, and 5, respectively.

\section{Motility percentage}

The mean sperm motility of the current study was $81.67 \pm 0.93 \%$ at the fresh stage. This value significantly $(p<0.05)$ declined to $77.33 \pm 0.83$ and $44 \pm 2.45 \%$ at the pre-freezing and freezing stage, respectively.

\section{Live sperm percentage}

At the initial stage of semen samples, the average percentage of live sperm was $91.27 \pm 0.57 \%$. This value was reduced significantly $(p<0.05)$ at $73.67 \pm 0.86$ and $48.1 \pm 0.76 \%$ respectively during pre-freezing and freezing stages.

\section{Normal morphology percentage}

The morphologically normal sperm was $85.27 \pm 0.64$ percent in the fresh semen samples. This value decreased considerably at the pre-cooling stage $(p<0.05)$ to $83.13 \pm 0.74 \%$. Although at the freezing stage the normal percentage morphology of semen samples was decreased to $80.2 \pm 1.28 \%$, they were not significantly decreased $(p>0.05)$.

\section{Intact Plasma membrane percentage}

At a fresh phase of semen samples, a total of $82.4 \pm 0.77 \%$ sperm contained intact plasma membrane. This mean value of the average sperm percentage $(p>0.05)$ reduces significantly in the pre-freezing and freezing stages of cryproduction to $69.73 \pm 0.92$ percent and $56.47 \pm 1.15$ percent.

\section{Intact acrosome percentage}

In fresh semen samples, sperm had intact acrosomes of $95.8 \pm 0.39 \%$. At pre-freezing and freezing, the percentage of sperm with intact acrosomes was $91.27 \pm 0.37$ and $77.4 \pm 0.81$ percent. The percentage of intact acrosomes was significantly different in both phases of cryo-production $(p>0.05)$.

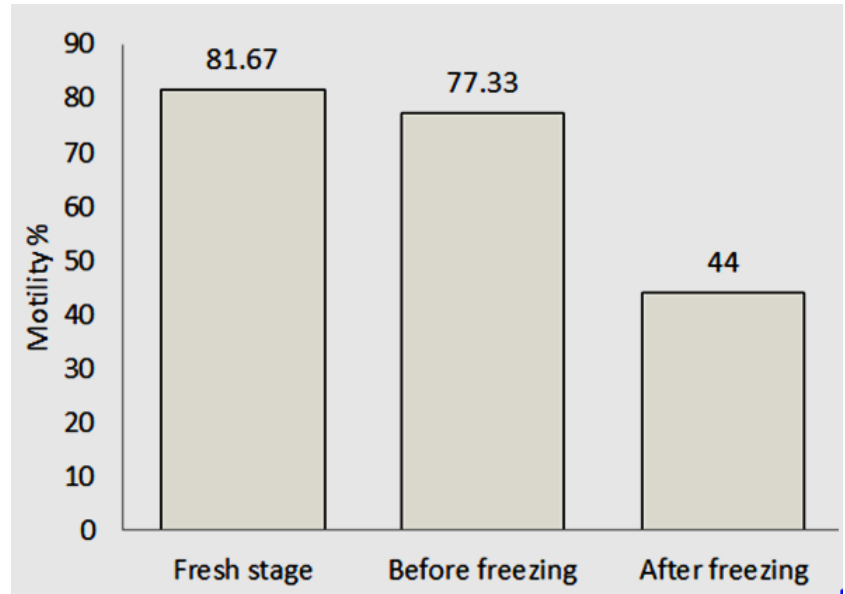

Figure 1 - Sperm motility changes at different stages of cryo-freezing

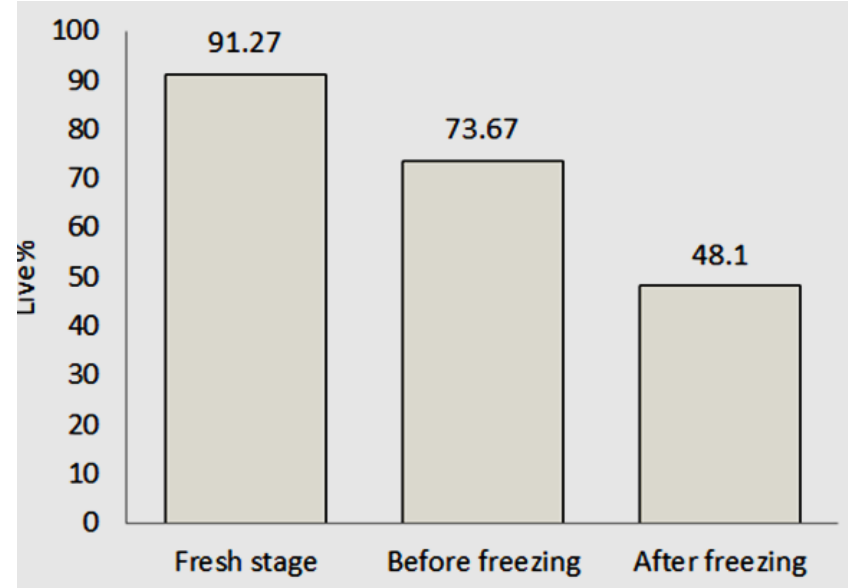

Figure 2 - Live sperm changes at different stages of cryofreezing 

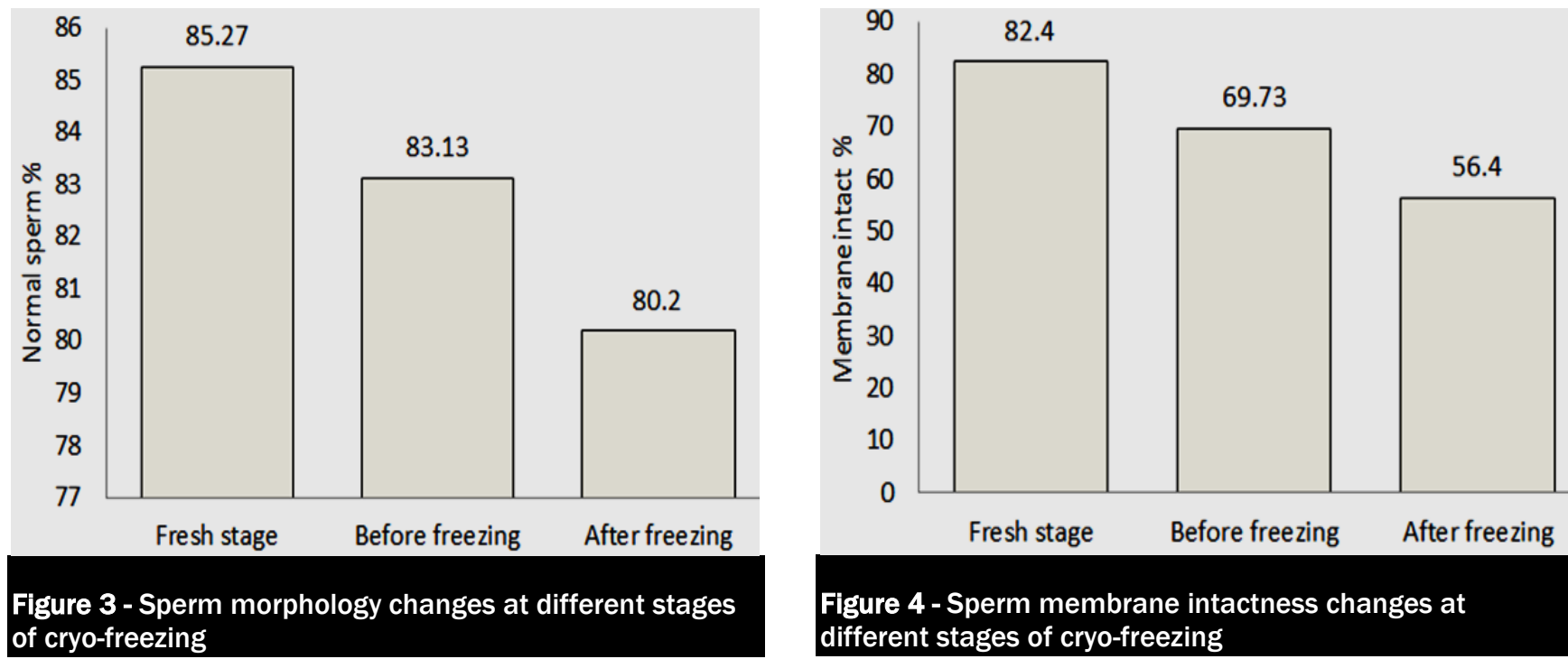

\section{of cryo-freezing}

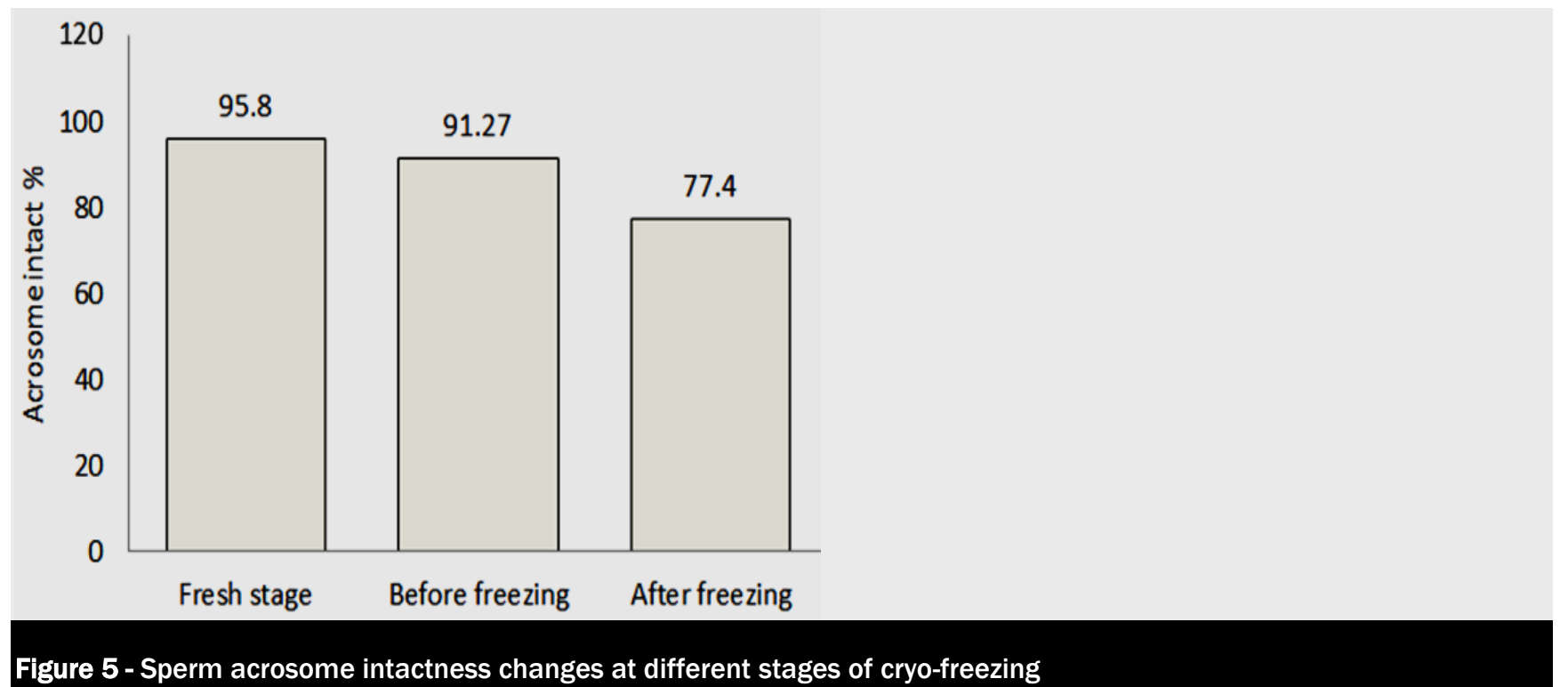

\section{DISCUSSION}

The small shepherds in Bangladesh had largely native sheep that are sparsely distributed in many agro-ecological regions, such as coastal areas, barind areas, northeast wetlands, Sundarbans-delta, and riverside basins (Pervage et al., 2009). Due to socioeconomic reasons, the owner castrates their male lambs at an early age or they sole their young rams for instant cash income which results from a severe shortage of breeding rams or provoke inbreeding with poor quality small rams. In this point, the author has acknowledged the similar observations of Rahman et al. (2015) and Tejaswi et al. (2016). Now a day in Bangladesh, in the western border areas such as Meherpur, Choadanga, and Chapainawabganj Districts, a crossbred Indian exotic Muzaffarnagari is popularly rearing for rapidly growing quality. The present study intended to evaluate the quality change during cryo-production of the semen samples with this exotic Muzaffarnagari breed rams before use in artificial insemination. So far present citation, this study reports in detail, for the first time, changes in sperm quality during semen production during fresh, pre-freeze, and freezing phase. In this trial, the percentage of motility has decreased from the initial and pre-freeze stage $(81.67 \pm 0.93$ and $77.33 \pm 0.83$ percent) by up to $44 \pm 2.45$ percent following freezing and thawing.

In Bangladeshi native ram and Deccani ram semen, Mahmuda et al. (2015) and Jha et al. (2018) found $79.8 \pm 3.4$ 84.9 \pm 4.0 and $74.7 \pm 3.9-87.0 \pm 4.5$ percent sperm motility in Bangladeshi native ram and Rajashri et al. (2017) observed $74.7 \pm 3.9-87.0 \pm 4.5$ percent sperm motility, respectively. These observations suggested the present findings. The present pre-freeze findings were in line with Mahmuda et al. (2015) in Bangladeshi native ram semen (71.3 $\pm 2.1-76.1 \pm 3.4 \%)$, Ahmadi Hamedani et al. (2016) in Zel ram semen (72.8 $\pm 1.15 \%)$, and Khalil et al.(2020) in Ossimi ram semen (73.30 \pm 2.50$)$. Awassi ram's observations by Haiat et al. (2006) suggested the freezing motility of this study (35 to 50 percent), Snyman and Jooste (2020) in Angora goat (35-50\%), and Valente et al. (2010) in freeze semen motility (36.9 $\pm 11.1-46.5 \pm 5.3 \%)$. Destructions to the sperm structure, changes in fluidity in the membrane, intracellular ice crystalline formation, and enzymatic activity may be the reasons for motility reduction at this stage of semen quality (Mazur, 1984).

The living sperm is mobile, while the dead are non-motile sperm. It is not primarily important to estimate the percentage of live sperm in semen simply. It needs to check the sperm for viability specifically when greater than $50 \%$ of sperm are immotile. During cryo-preservation of semen samples, the spermatozoa might have to go through various 
adverse conditions and the assessment of quality changes is of production concerned. The percentage of live sperm in fresh semen samples confirmed by earlier researchers' observations, Mahmuda et al. (2015), Hossain et al. (2016), and Jha et al. (2018) in Bangladeshi native rams to be $84.5 \pm 3.7-90.0 \pm 4.0,87.9 \pm 2.5-90.01 \pm 3.2$, and $79.7 \pm 3.6-94.7 \pm 1.0$ $\%$, respectively. Furthermore, the current findings were also agreed with Boediono et al. (2004) and Azubuike et al. (2017) in Garut and Yankasa rams to be $91.5 \pm 3.1$ and $87.50 \pm 1.64 \%$, respectively. The reduction in live spermatozoa at the prefreeze stage was consensus with Mahmuda et al. (2015), Ahmadi Hamedani et al. (2016), and Kurmi et al. (2018) to be $74.9 \pm 2.6$ - 81.0 \pm 4.1 and $76 \pm 1.22 \%$ in Bangladeshi native and Zel rams, respectively. These differences may be due to the effects of cooling temperature. In the current study, it was experienced that the freezing temperature might have disruptive effects on sperm survivability that incurred up to $48.1 \pm 0.76 \%$ reduction of live sperm during cryopreservation. The present finding on frozen live sperm percentage was suggested by the frozen quality in live sperm studied by Mahmuda et al. (2015) in Bangladeshi native ram (45.4 $\pm 0.7-46.4 \pm 0.5)$ and Khalil et al. (2020) in Ossimi ram

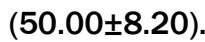

Poor morphological scores of sperm are highly controversial in their practical implications. Many researchers had opined on the amount of morphologically normal sperm in useable semen samples. Rai et al. (2020), reported that most impairments in fertilization rates occurred with morphological abnormal sperm since better scores in livestock frozen semen have less than $25 \%$. A semen smear stained with the eosin nigrosin can be used to measure normal and abnormal morphological sperm forms in the ejaculate quantitatively. The smeared slide is calculated based on specific abnormalities in the head, tail, and mid-piece for the morphological appearance of sperm. The current observations stated that the change in normal sperm morphology significantly occurs when the temperature goes down from $37^{\circ} \mathrm{C}$ to $5^{\circ} \mathrm{C}$ and the further reduction in temperature has little effects on sperm morphology but is not significant. The previous findings of Mahmuda et al. (2015) and Hossain et al.(2016) in Bangladeshi native rams $(80.7 \pm 2.2-86.3 \pm 3.7$ and $84.9 \pm 3.3-86.4 \pm 2.1 \%$, respectively) at the fresh stage were correlated the present findings. The pre-freeze findings of Mahmuda et al. (2015) in Bangladeshi native ram (76.9 $2.3-81.0 \pm 2.5 \%)$ and Ahmadi Hamedani et al. (2016) in Zel ram $(81.6 \pm 0.67 \%)$ were in line with the present pre-freeze findings. At the freezing stage, quality in sperm morphology was in agreement with the findings of Mukherjee et al. (2016) in garole ram where abnormal sperm percentages were lower $(8.08 \pm 0.1 \%)$ than our findings.

The intactness of the sperm membrane is very important for its survivability during freezing and fertilization. Jeyendran et al. (1984) described this hypoosmotic swelling test protocol for assessing the sperm functional integrity. At the freezing stage, intact sperm percent decreased in the current study from the fresh and pre-freezing phase. The damage and decrease of lipid components in the sperm cell membrane by lowered chilling and freezing temperature, and this statement is under Holt and North (1984) in case of buck semen freezing. The current finding of intact sperm membrane coincided with Hossain et al. (2016) and Jha et al. (2018) in Bangladeshi native ram (84.7 \pm 0.5 and $71.2 \pm$ 4.4 - $88.5 \pm 5.6 \%$ ); Valente et al. (2010) in ram semen samples (85.4 $\pm 5.2-86.9 \pm 5.4 \%)$ at the fresh stage. The prefreeze sperm membrane intactness was in line with Ahmadi Hamedani et al. (2016) in Zel ram (71.40 \pm 0.97$)$, Kurmi et al. (2018) in Chhotanagpuri (70.06 \pm 0.12$)$, and Khalil et al. (2020) in Ossimi rams (68.60 \pm 2.78$)$. The membrane intactness of spermatozoa at the frozen stage was in agreement with the freezing quality of Garole ram semen $(55.00 \pm$ $0.5 \%)$ and Ossimi ram semen $(51.70 \pm 8.11 \%)$ observed by Mukherjee et al. (2016) and Khalil et al. (2020), respectively.

The knowing significance of sperm acrosome status is of paramount importance for successful fertilization. A live sperm without an intact acrosome cannot fertilize an ovum. Therefore a certain percentage of sperm with a normal acrosome needs to be present in quality frozen semen. The current finding shows that the temperature change from $35^{\circ}$ $\mathrm{C}$ to $5^{\circ} \mathrm{C}$ during the cooling and the glycerol balance affects acrosome intactness less but that the frozen temperature has an important impact on the acrosome integrity. Such type of reduction of the intact acrosome of frozen semen samples of the current study was suggested by the earlier researcher, Jha et al. (2020) in frozen indigenous ram semen were $74.44 \pm$ $1.94-76.13 \pm 1.42 \%$. As per citation, Mukherjee et al. (2016), found better-frozen semen quality in Garole ram with an intact acrosome of $84.30 \pm 0.8 \%$ than the present findings. These higher and better findings might have resulted from the variation in extender, freezing and thawing system, and breeds of ram.

\section{CONCLUSION AND RECOMMENDATION}

In conclusion, the cooling from $37^{\circ} \mathrm{C}$ to $5^{\circ} \mathrm{C}$ harms the overall changes of ram spermatozoa and semen quality. The maximum change in normal morphology and acrosome integrity mainly occurs during chilling and equilibration from the fresh stage to the pre-freeze stage while little change occurs at the freezing stage. The other trait's quality importantly changes all way the cryo-freezing stages. To minimize the cryo-damage in ram spermatozoa, another or re-furnished freezing protocol concerning freezing rate, use of different extenders, and addition of membrane stabilizers might be potential areas for future investigation. Moreover, the determination of ultra-biochemical structures at different stages of cryo-freezing should be studied for a better understanding of their more detailed effects on ram semen.

\section{DECLARATIONS}

\section{Corresponding author}

Farida Yeasmin BARI: Email: faridabari06@gmail.com; (DORCID: 0000-0002-1574-9263

\section{Authors' contribution}

FY Bari contributed to the concept of the manuscript. M Asaduzzaman performed and wrote up the study. A Saha, S Biswas, and S Akter assisted in performing the study, data arranging, and calculation. MGS ALAM and all other authors read and approved the manuscript's contents. 


\section{Acknowledgments}

The author is greatly acknowledged to the reproduction personnel and staff of the Department of Surgery and Obstetrics, Bangladesh Agricultural University, Mymensingh-2202.

Conflict of interests

The authors declare that they have no competing interests.

\section{REFERENCES}

Aboagla EME and Terada T (2004). Effects of egg yolk during the freezing step of cryopreservation on the viability of goat spermatozoa. Theriogenology, 62(6): 1160-1172. DOI: https://doi.org/10.1016/j.theriogenology.2004.01.013

Acharya M (2017). Improvement in simple artificial insemination in sheep using chilled extended semen and consideration of fertility in ewes. Theses and Dissertations 2502. http://scholarworks.uark.edu/etd/2502

Agarwal A, Majzoub A, Esteves SC, Ko E, Ramasamy R, and Zini A (2016). Clinical utility of sperm DNA fragmentation testing: practice recommendations based on clinical scenarios. Translational andrology and urology, 5(6): 935-950. DOI: https://doi.org/10.21037/tau.2016.10.03

Ahmad M, Nasrullah R, Riaz H, Sattar A and Ahmad N (2014). Changes in motility, morphology, plasma membrane, and acrosome integrity during stages of cryopreservation of buck sperm. Journal of the South African Veterinary Association, 85(1): 01-04. Dol: https://doi.org/10.4102/jsava.v85i1.972

Ahmadi Hamedani M, Tahmasbi AM, Naserian A A and Ahangari Y J (2016). Evaluation of vitamin E on microscopic parameters of chilled and frozen stored ram semen. Der Pharma Chemica, 8(6):16-22. https://www.derpharmachemica.com/pharma-chemica/evaluation-of-vitamine-on-microscopic-parameters-of-chilled-and-frozen-stored-ram-semen.pdf

Ax RL, Dally MA, Lenz RW, Love CC, Varner DD, Hafez B and Bellin ME (2000). Semen evaluation. In: Hafez, B., Hafez, E.S.E., Eds.2000. Reproduction in Farm Animals.7th ed., Lippincott Williams and Wilkins, Philadelphia.365-375. DOI: https://doi.org/10.1002/9781119265306.ch25

Azubuike US, David O, Ibrahim RP, Sankey RJ, Chika Cl, and Ikechukwu ES (2017). Semen Characteristics of Yankasa Rams Following Cypermethrin Treatment. European Journal of Clinical and Biomedical Sciences, 3(3): 53-58. D0I: https://doi.org/10.11648/j.ejcbs.20170303.11

Barth $A D$ and Oko RJ (1989). Abnormal morphology of bovine spermatozoa. lowa State University Press. https://www.worldcat.org/wcpa/rel20210825/images/icon-bks.gif

Boediono A (2004). Preservation of Garut Rams Spermatozoon as a Source of Male Germ Plasm. BIOTROPIA-The Southeast Asian Journal of Tropical Biology, 23:40-46. DOI: https://dx.doi.org/10.11598/btb.2004.0.23.200

Brito LF, Barth AD, Bilodeau-Goeseels S, Panich PL, and Kastelic JP (2003). Comparison of methods to evaluate the plasmalemma of bovine sperm and their relationship with in vitro fertilization rate. Theriogenology, 60(8): 1539-1551. D0I: https://doi.org/10.1016/s0093691x(03)00174-2

Cabrera F, Gonzalez F, Batista M, Calero P, Medrano A and Gracia A (2005). The effect of removal of seminal plasma, egg yolk level and season on sperm freezability of canary buck (Capra hircus). Reproduction in Domestic Animals, 40(3):191-5. D0I: http://dx.doi.org/10.1111/j.1439-0531.2005.00544.x

Colenbrander B, Gadella BM and Stout TA (2003). The predictive value of semen analysis in the evaluation of stallion fertility. Reproduction Domestic Animal, 38: 305-311. https://doi.org/10.1046/i.1439-0531.2003.00451.X

Cremades T, Roca J, Rodriguez - Martinez H, Abaigar T, Vazquez JM and Martinez EA (2005). Kinematic changes during the cryopreservation of boar spermatozoa. Journal of Andrology, 26(5): 610-618. DOI: https://doi.org/10.2164/jandrol.05028

Curry MR (2000). Cryopreservation of semen from domestic livestock. Reviews of reproduction, 5(1): 46-52. https://pubmed.ncbi.nlm.nih.gov/10711735/

Evan G and Salmons WMC (1987). Salamon"s Artificial insemination of sheep and goats. Published by Butterworths in Sydney, Boston. https://byjysenypymok.mybookink.icu/salamons-artificial-insemination-of-sheep-and-goats-book-10662jc.php\#edition

Flesch FM and Gadella BM (2000). Dynamics of the mammalian sperm plasma membrane in the process of fertilization. Biochimica et Biophysica Acta (BBA)-Reviews on Biomembranes, 1469(3):197-235. D0I: https://doi.org/10.1016/S0304-4157(00)00018-6

Haiat N, Ababneh M, Hailat SL, Shidiafat F, Abed-Raheem A, Al-Rasiq Khalifeh A, Al-Rasiq, Al-Abdeen AZ (2006). Final Report on Al: Improving Awassi Sheep Productivity by Using Frozen Semen in Jordan, Egypt, and Palestinian Authority. Retrieved from https://www.g77.org/pgtf/finalrpt/INT-01-K02-FinalReport.pdf

Holt WV and North RD (1984). Partially irreversible cold-induced lipid phase transitions in mammalian sperm plasma membrane domains: Freeze-fracture study. Journal of Experimental Zoology, 230(3): 473-483. DOI: https://doi.org/10.1002/jez.1402300316

Hossain A, Islam MM, Naznin F, Ferdousi RN, Bari FY and Juyena NS (2016). Quality of ram spermatozoa separated with the modified swim-up method. Bangladesh Veterinarian, 33(2): 62-70. DOI: https://doi.org/10.3329/bvet.v33i2.36459

Isachenko E, Isachenko V, Katkov II, Dessole S, Nawroth F (2003). Vitrification of mammalian spermatozoa in the absence of cryoprotectants from past practical difficulties to present success. Reproductive Biomedicine Online, 6(2):191-200. D0I: http://dx.doi.org/10.1016/S1472 6483(10)61710-5

Jeyendran RS, Van der Ven HH and Zaneveld LD (1992). The hypoosmotic swelling test: an update. Archives of Andrology, 29(2): 105-116. DOI: https://doi.org/10.3109/01485019208987714

Jeyendran RS, Van der Ven HH, Perez-Pelaez M, Crabo BG and Zaneveld $U$ (1984). Development of an assay to assess the functional integrity of the human sperm membrane and its relationship to other semen characteristics. Journal of Reproduction and Fertility, 70(1): 219-228. DOI: https://doi.org/10.1530/jrf.0.0700219

Jha PK, Alam M, Al-Mansur M A, Islam M and Bari F (2018). Selection of breeding rams by evaluating semen quality. Journal of Applied Animal Science, 11(1): 9-20. http://www.vs.mahidol.ac.th/jaas/File...

Jha PK, Golam Shahi Alam M and Bari FY (2020). A comparison of freezing methods and diluents types on post-thaw sperm quality of ram sperm. Research in Agriculture, Livestock and Fisheries, 7(2): 235-241. DOI: https://doi.org/10.3329/ralf.v7i2.48863 
Jha PK, Shahi Alam MG, Mansur AA, Naher N, Islam T, Uddin Bhuiyan M and Bari FY (2019). Cryopreservation of Bangladeshi ram semen using different diluents and manual freezing techniques. https://www.sciencedirect.com/science/article/pii/S0011224019300525

Khalil WA, Abdel-Khalek AKE, Falchi L, El-Saidy BE and Yousif Al (2020). Effects of extender and packaging method on morphological and functional characteristics of cryopreserved Ossimi ram semen. Asian Pacific Journal of Reproduction, 9(3): 148 https://www.apjr.net/text.asp?2020/9/3/148/284277

Kurmi DJ, Sinha MP, Kumar R, Hazarika SB, Dewry RK and Gohain S (2018). Effect of vitamin E on the quality of frozen ram semen. Theriogenology Insight-An International Journal of Reproduction in all Animals, 8(1): 39-43. https://www.apjr.net/text.asp?2020/9/3/148/284277

Leboeuf B, Restall B and Salamon S (2000). Production and storage of goat semen for artificial insemination. Animal Reproduction Science, 62(1-3): 113-141. https://doi.org/10.1016/S0378-4320(00)00156-1

Mahmuda BBA, Azizunnesa, BF Zohara, MGS Alam and FY Bari (2015). Effect of preservation time on the quality of frozen semen in indigenous rams. Bangladesh Journal of Animal Science, 44: 10-15. DOI: http://dx.doi.org/10.3329/bjas.v44i1.23113

Mazur P (1984). Freezing of living cells: mechanisms and implications. American Journal of Physiology-Cell Physiology, 247(3): C125-C142. DOI: https://doi.org/10.1152/ajpcell.1984.247.3.c125

Medeiros ASL, Gomes GM, Carmo MT, Papa FO and Alvarenga MA (2002). Cryopreservation of stallion sperm using different amides. Theriogenology, 58: 273-276. DOI: http://dx.doi.org/10.1016/S0093-691X(02)00898-1

Mir SS, Lone FA, Khan MZ, Malik AA, Islam R and Sofi KA (2012). Effect of cold storage period on the quality of ram cauda epididymal spermatozoa recovered postmortem. Turkish Journal of Veterinary and Animal Sciences, 36(6): 683-687. D0I: http://dx.doi.org/10.3906/vet-1107-21

Moghaddam GH, Pourseif MM and Rafat SA (2012). Seasonal variation in semen quantity and quality traits of Iranian crossbred rams. Slovak Journal of Animal Science, 45(3): 67-75. http://www.vuzv.sk/slju/12-3/1-Moghaddam-SJAS-3-2012.pdf

Mukherjee KP, Basu S, Sahoo AK, Datta U, Ray K and Chattaraj S (2016). Cryoprotective effect of EDTA, lactose, ascorbic acid, and L-cysteine as additives on garole ram (Ovis aries) semen. International Journal of Advanced Research in Biological Science, 3(7): 92-98. https://ijarbs.com/pdfcopy/july2016/ijarbs13.pdf

Ōura $\quad \mathrm{a}$ and Toshimori K (1990). International Review of Cytology, Elsevier. pp:105-151. https://www.sciencedirect.com/bookseries/international-review-of-cytology

Pervage S, Ershaduzzaman M, Talukder MAI, Hasan MN and Khandoker MAMY (2009). Phenotypic characteristics of indigenous sheep of Bangladesh. Bangadesh Journal of Animal Science, 38(1\&2): 1-6. DOI: https://doi.org/10.3329/bjas.v38i1-2.9906

Purdy PH (2006). A review on goat sperm cryopreservation. Small Ruminant Research, 63(3): 215-225. https://doi.org/10.1016/i.smallrumres.2005.02.015

Rahman HMR, Paul AK, Maruf AA, Rahman MM, Islam MT and Bari FY (2015). Characterization of native ram semen in Bangladesh. Wayamba Journal of Animal Science, 7:1076-1083. http://www.wayambajournal.com/documen...

Rai S, Alex R, Karunakaran M and Behera R (2020). Quality determination of frozen semen before use for Al in domestic animals. Central Institute for Research on Cattle, Meerut. Retrieved from https://vikaspedia.in/agriculture/livestock/cattle-buffalo/breeding-management1/quality-determination-of-frozen-semen-before-use-for-artificial-insemination-in-domestic-animals

Rajashri M, Reddy KR, Kumar GA, Kumari NN, Kesharwani S and Srinivas G (2017). Qualitative ultrastructural changes and morphometry of Deccani sheep spermatozoa preserved with egg yolk citrate extender. Journal of Applied and Natural Science, 9(3):1515-1521. DOI: http://dx.doi.org/10.31018/jans.v9i3.1394

Ramu S, Jeyendran RS (2013). The Hypo-osmotic Swelling Test for Evaluation of Sperm Membrane Integrity. In: Carrell D., Aston K. (eds) Spermatogenesis. Methods in Molecular Biology (Methods and Protocols), vol 927. Humana Press, Totowa, NJ. Dol: https://doi.org/10.1007/978-1-62703-038-0 3

Rasul Z, Ahmad N and Anzar M (2001). Changes in motion characteristics, plasma membrane integrity, and acrosome morphology during cryopreservation of buffalo spermatozoa. Journal of Andrology, 22(2): 278-283. DOI: http://dx.doi.org/10.1002/j.19394640.2001.tb02181.x

Sitali MC, Mwanza AM, Mwaanga ES, Parsons IR and Parsons NJ (2017). Effects of Age, Breed and Scrotal Circumference Interactions on Sperm Morphology of Bulls Raised on Commercial Farms in Zambia. Theriogenology Insight-An International Journal of Reproduction in all Animals, 7(3): 161-168. DOI: http://dx.doi.org/10.5958/2277-3371.2017.00033.X

Snyman MA and Jooste F (2020). Semen freezing and subsequent insemination results in South African Angora goats. Grootfontein Agric, 20(1): 15-27. Article link

Soltanpour F and Moghaddam G (2013). Effects of frozen diluents on storage of ram sperm. International journal of Advanced Biological and Biomedical Research, 1(12): 1698-1704. http://citeseerx.ist.psu.edu/viewdoc/download?doi=10.1.1.1041.8154\&rep=rep1\&type=pdf

Tejaswi V, Narayanaswamy M and Sagar NG (2016). Studies on certain fresh semen characteristics in rams of Indian twining breed-the Nari Suvarna during winter months (short photoperiod). International Journal of Science, Environment and Technology, 5(3): 1697- 1706. https://www.ijset.net/journal/1054.pdf

Valente SS, Pereira R M, Baptista MC, Marques CC, Vasques MI, Pereira M S, and Barbas, JP (2010). In vitro and in vivo fertility of ram semen cryopreserved in different extenders. Animal Reproduction Science, 117(1-2): https://doi.org/10.1016/j.anireprosci.2009.04.007

VGO 511: Veterinary Andrology and Reproductive Techniques (1+1). (2012, June 4). Retrieved from http://ecoursesonline.iasri.res.in/mod/page/view.php?id=75217

Vishal KP (2014). Evaluation of semen characteristics and fertility in Nellore sheep (Jodipi) (Doctoral dissertation, Sri Venkateswara Veterinary University Tirupati-517 502. (AP) India). http://krishikosh.egranth.ac.in/handle/1/5810030332

Watson PF (2000). The causes of reduced fertility with cryopreserved semen. Animal Reproduction Science, 60-61: 481-492. Dol: https://doi.org/10.1016/s0378-4320(00)00099-3

Zohara BF, Bari F and MGS Alam (2014). Effects of the proportion of egg yolk and preservation time on chilled Semen from Indigenous Rams. GSTF Journal of Veterinary Science, 1(1): 18-26. http://dl6.globalstf.org/index.php/jvet/article/viewFile/93/2409 